\title{
VALORIZAÇÃO, PRECARIZAÇÃO E RECONHECIMENTO DOS PROFESSORES DE CRECHES UNIVERSITÁRIAS
}

\author{
VALORIZACIÓN, PRÁCTICA Y RECONOCIMIENTO DE PROFESORES DE \\ CRECHES DE LA UNIVERSIDAD
}

\author{
VALORIZATION, PRACTICE AND RECOGNITION OF UNIVERSITY CRECHES \\ TEACHERS
}

\author{
Silvânia Brito ARAÚJO ${ }^{1}$ \\ Ennia Débora Passos Braga PIRES ${ }^{2}$ \\ Geovania Fagundes RIBAS ${ }^{3}$
}

RESUMO: Este artigo é um recorte de pesquisa de mestrado cujo objetivo foi discutir Políticas Públicas para Educação Infantil: implementação de creches universitárias na Universidade Estadual do Sudoeste da Bahia (UESB). Trata-se de uma pesquisa qualitativa com aporte teórico no materialismo histórico dialético. Os dados foram coletados através de entrevistas semiestruturadas e análise de documentos legais e normativos da Instituição estudada. O estudo revela que as creches da UESB enfrentam dilemas desde a implementação, há trinta anos, sejam: a falta de valorização profissional, a precarização dos contratos trabalhistas e a falta de reconhecimento desses espaços no interior da instituição como campo de pesquisa e de formação para alunos da própria universidade.

PALAVRAS-CHAVE: Políticas públicas. Educação infantil. Creche universitária.

RESUMEN: Este texto es un recorte de investigación de maestría cuyo objetivo fue discutir Políticas públicas para la educación infantil temprana: implementación de guarderías universitarias en la Universidad Estatal del Suroeste de Bahía (UESB). Es una investigación cualitativa con una contribución teórica en el materialismo histórico dialéctico. Los datos se recopilaron a través de entrevistas semiestructuradas y análisis de documentos legales y normativos de la institución estudiada, que revela que las guarderías de la UESB han enfrentado dilemas desde la implementación, durante 30 años, de: falta de valorización profesional, precariedad de los contratos laborales y la falta de reconocimiento de estos

${ }^{1}$ Universidade Estadual do Sudoeste da Bahia (UESB), Vitória da Conquista - BA - Brasil. Programa de Pósgraduação em Educação (PPGED/UESB). Coordenadora Pedagógica da Educação Infantil do Núcleo Pedagógico do Município de Vitória da Conquista. Mestre em Educação pela UESB. Membro do Grupo de Pesquisa LUDIPPE - Ludicidade, Didática, Política e Práticas de ensino. OrcID: http://orcid.org/0000-0002-7511-6257. E-mail: silbaraujo@yahoo.com.br

${ }^{2}$ Universidade Estadual do Sudoeste da Bahia (UESB), Vitória da Conquista - BA - Brasil. Docente do Departamento de Ciências Humanas, Educação e Linguagem e do Programa de Pós-Graduação em Educação (PPGED/UESB). Doutora em Educação pela UNICAMP. Líder do Grupo de Pesquisa LUDIPPE - Ludicidade, Didática, Política e Práticas de Ensino. OrcID: http://orcid.org/0000-0003-3924-4996. E-mail: enniadebora@uesb.edu.br

${ }^{3}$ Universidade Estadual do Sudoeste da Bahia (UESB), Vitória da Conquista - BA - Brasil. Programa de Pósgraduação em Educação (PPGED/UESB). Docente do Instituto Federal de Ciências e Tecnologia da Bahia. Mestre em Educação pela UESB. Membro do Grupo de Pesquisa LUDIPPE - Ludicidade, Didática, Política e Práticas de ensino. OrcID: http://orcid.org/0000-0001-8335-010. E-mail: geoeduca.ifba@gmail.com 
espacios dentro de la institución como un campo de investigación y formación para estudiantes universitarios.

PALABRAS CLAVE: Políticas públicas. Educación infantil. Guardería universitaria.

ABSTRACT: This article is a master's research clipping whose objective was to discuss Public Policies for Early Childhood Education: implementation of university daycare centers at the State University of Southwest of Bahia (UESB). It is a qualitative research with a theoretical contribution in dialectical historical materialism. Data were collected through semi-structured interviews and analysis of legal and normative documents of the studied institution. The study reveals that the UESB daycare centers have faced dilemmas since the implementation, for 30 years, of: lack of professional valorization, precariousness of labor contracts and the lack of recognition of these spaces within the institution as a field of research and training for university students.

KEYWORDS: Public policies. Child education. University nursery.

\section{Introdução}

Este artigo analisa a implementação das creches universitárias na Universidade Estadual do Sudoeste da Bahia (UESB) com o propósito de discutir os processos adotados pela universidade a partir das políticas públicas da Educação infantil para a implementação de suas creches e refletir sobre os dilemas enfrentados por essas unidades de Educação Infantil.

Historicamente, a Educação Infantil apresenta uma trajetória descontínua, não linear, assim como toda a educação brasileira, decorrente das transformações econômicas, políticas, culturais e sociais a nível mundial. A criação da Educação Infantil nos remete ao lugar específico da creche, cujo surgimento no Brasil remonta ao século XX (HADDAD, 1993). É no cenário da década de 70 e 80 do século passado, diante do processo de urbanização e industrialização, que se verifica o aumento crescente do número de mulheres no mercado de trabalho e a eclosão dos movimentos sociais e feministas que ocorre em virtude da expansão da demanda por contextos coletivos destinados à educação das crianças pequenas. $\mathrm{O}$ reconhecimento da creche como um espaço especializado para atender e educar as crianças de 0 a 6 anos de idade contribuiu para que houvesse um amplo processo de criação de instituições, tanto privadas como governamentais, destinadas ao atendimento da Educação Infantil.

A constatação de que a mulher é chamada a participar do mercado de trabalho em expansão e a falta de um aparato social que lhe garanta desenvolver suas atividades profissionais de forma plena, bem como conciliá-los com suas atribuições de mãe, impulsionaram as reivindicações por creches no local de trabalho. 
Em consonância com a dinâmica da história da creche, suas demandas foram pauta de reivindicações dos movimentos sociais, sobretudo no Movimento Feminista e no Movimento de Luta por Creche, os quais advogavam a ideia de creche como um direito social das mães trabalhadoras e como uma instituição a ser mantida pelo Estado, resguardando, dessa forma, o seu caráter público. Nesse período, inicia-se a história das creches no interior das universidades, para responder às reivindicações das mães funcionárias dessas instituições por locais apropriados, onde pudessem deixar seus filhos enquanto trabalhassem.

Foi nesse contexto de lutas sociais que as creches universitárias foram criadas no âmbito da política de benefício social, como forma de atender às demandas da comunidade universitária. O êxito da creche, naquele momento, ocorreu como um direito da mulher trabalhadora, feminista, empregada de empresa privada, funcionária pública, e pelos sindicatos. Conforme Haddad (1993), a década de 70 caracterizou-se pela eclosão de vários movimentos sociais, e, em alguns lugares, a creche representou forte apelo, passando a ser reivindicada como um direito das mulheres trabalhadoras.

De acordo com estudos de pesquisadoras como Rosemberg (1992), Fagundes (1997), Raupp (2002), dentre outras(os), a reivindicação por creches no ambiente de trabalho passa a ser bandeira de organizações políticas lideradas por mulheres que buscavam espaços próximos aos locais de trabalho e estudo para deixar as crianças.

No documento que trata da implementação das creches na Universidade Estadual do Sudoeste da Bahia (UESB, 1988), encontramos a justificativa que não destoa do contexto histórico de outras creches universitárias, mas demarca o surgimento da creche nos locais de trabalho como uma conquista das lutas dos trabalhadores, respaldando-se na legislação brasileira, tendo como base a CLT de 1943, que determinava que as empresas com mais de 30 mulheres deveriam ter um lugar para a guarda das crianças durante o período de amamentação. É importante reafirmar que a creche, na UESB, seguiu o modelo assistencialista, visando apenas à guarda e ao cuidado das crianças pequenas. A instituição possui duas creches localizadas em dois de seus campi, sendo referenciadas neste trabalho como creche Campus 1 e creche Campus 2. O documento de implementação da creche Campus 1 da UESB apresenta como finalidade maior a guarda e assistência aos filhos de funcionárias e professoras em seu turno de trabalho na Instituição (UESB, 1988).

Após dez anos da implantação da primeira creche, a UESB implanta a segunda no Campus 2, tendo como objetivo inicial "proporcionar assistência e guarda à criança na faixa de quatro meses a seis anos, filhos de professores e funcionários da UESB” (UESB, 1998). 
Constata-se, portanto, que a implementação das creches na UESB pautou-se primeiramente na assistência à necessidade da mulher, ligada ao trabalho extradomiciliar, uma demanda recorrente do mundo capitalista. $\mathrm{O}$ atendimento à criança, o cuidado e as diretrizes do trabalho educativo não ocupam espaço central nos documentos de criação dessas creches, despertando o interesse em conhecer quais dos impactos dessa concepção na trajetória dessas unidades de Educação Infantil.

\section{Metodologia}

Para o desenvolvimento do trabalho optamos pela pesquisa de cunho qualitativo com aporte no Materialismo Histórico Dialético na condição de método de análise, pois as determinações que constituem a realidade do objeto apresentam a sua essência, em um primeiro momento, de forma aparente, empírica. Posteriormente, a abstração dessas determinações permite ao pesquisador ir além das aparências, visto que busca conhecer essa realidade em sua essência. Nesse sentido, vai além da investigação estrita das causas, das origens, pois procura compreender as razões da existência do fenômeno em sua totalidade histórica, explicar sua origem, suas intersubjetividades, mudanças e as inter-relações que se estabelecem, além de se preocupar com a relevância social do objeto.

Esse método se justifica pelo fato de a sociedade ser naturalmente conflituosa e as relações estabelecidas no processo de conhecimento do sujeito e objeto acontecerem em relações dialéticas.

Como instrumentos de pesquisa utilizamos a análise documental e a entrevista semiestruturada, por considerá-las estratégias mais adequadas para a realização da coleta de dados desta investigação. Segundo Lüdke e André (1986), a análise documental possui algumas prerrogativas, pois os documentos são fontes estáveis e ricas, e permanecem mesmo com o passar dos anos; podem ser consultadas inúmeras vezes, a fim de embasar diferentes pesquisas, o que dá maior confiabilidade aos resultados alcançados; além disso, são fontes poderosas, das quais podem ser retirados dados relevantes que fundamentem as conclusões do pesquisador. Foi realizada a análise dos documentos que tratam da criação e implementação das creches na universidade Estadual do Sudoeste da Bahia, Regimento, Estatuto e Plano de Desenvolvimento Institucional - PDI (2013-2017), buscando compreender as concepções que embasam aquelas instituições e qual o papel que ocupam no organograma da instituição.

A opção pela entrevista semiestruturada justifica-se por entendermos que os sujeitos devem ser compreendidos com base em seu ponto de vista, na descrição dos fenômenos. Os 
sujeitos que fizeram parte desta investigação foram duas servidoras que atuam nas creches (sendo uma do Campus 1 e a outra do Campus 2) e quatro mães (duas do Campus 1 e duas do Campus 2 da UESB), tendo como critério de seleção: duas mães que tiveram seus filhos atendidos pelas creches nos primeiros anos de sua implementação e outras duas que os filhos estavam na creche no momento de realização da pesquisa, além de dois funcionários da universidade lotados no órgão ao qual as creches estão vinculadas. Os sujeitos foram referenciados neste trabalho por codinome, preservando, assim, suas identidades e garantindo o anonimato.

\section{Resultados e discussões}

A análise do documento de implementação e das entrevistas evidenciaram alguns pontos que reconhecemos como dilemas que pontuam o atendimento da creche da UESB desde a sua implementação até os dias atuais, tais como: valorização, precarização dos contratos trabalhistas e reconhecimento dos profissionais que atuam nesses espaços.

A questão da valorização profissional está intimamente ligada à questão do trabalho. Nesse sentido, o trabalho torna-se constitutivo do ser social, por meio do qual construímos a nossa humanidade e nos construímos como seres humanos.

Nessa perspectiva, tomemos como base os estudos do materialismo histórico dialético, que entende que o trabalho é, sem dúvida, o fator de distinção entre os seres humanos e as outras espécies.

Pode-se distinguir os homens dos animais pela consciência, pela religião que se queira. Mas eles começam a distinguir-se dos animais logo que começam a produzir seus meios de existência, e esse passo à frente é a própria consequência de sua organização corporal. Ao produzir seus meios de existência, os homens produzem indiretamente sua própria vida material (MARX; ENGELS, 1998, p. 10).

Marx (2002) acentua que o trabalho é um elemento indispensável à existência do homem. Por meio da ação consciente, ele se constitui como ser histórico e racional, independentemente da sociedade em que viva. $\mathrm{O}$ autor ressalta que o homem atua sobre a natureza e a modifica considerando suas necessidades. Dessa forma, o homem evolui pelo processo de trabalho, alterando sua própria natureza. Para Saviani (2005), o ser humano é uma construção social e histórica. Além disso, no capitalismo, o trabalho assume um caráter alienado, tornando-se um elemento de exploração de uma classe em relação à outra. 
Nesse sentido, ao ser questionada a respeito do regime de contrato trabalhista, a funcionária do Campus 1 assim respondeu:

Aqui nessa creche todos nós somos contratados. É um contrato de prestação de serviço, que eles chamam de CL - Contrato de Licitação. O período de contrato eu sei que é curto, só não sei te dizer o tempo, pois ele não é de responsabilidade da creche, é pela Universidade. Eu sei que a universidade consegue renovar automaticamente. Quando você entra, você assina um contrato para um período de 90 dias, aí vai sendo renovado por mais 90 . É a universidade que vai fazendo essa renovação automaticamente (MARGARIDA, Campus 1, 2018).

O depoimento da funcionária demonstra que, mesmo se tratando de uma universidade pública estadual, a forma de seleção para atender a Educação Infantil não ocorreu e nem ocorre atualmente por meio de concurso público, mas, sim, por uma seleção em forma de contrato temporário. Essa forma de contrato de trabalho, além de não oferecer benefício trabalhista algum para o trabalhador, não gera estabilidade funcional e não permite progressão de carreira. Portanto, a forma de contrato temporal flexibiliza a legislação social do trabalho e amplia as formas de precarização e destruição dos direitos sociais trabalhistas, que foram arduamente conquistados pela classe trabalhadora (ANTUNES; DRUCK, 2013). Outra entrevistada assim acrescenta:

Muitas vezes nos sentimos inferiores a alguns colegas aqui da instituição, não pelo nível de formação acadêmica e, sim, porque eles têm direitos ao plano de carreira. Podem traçar planos para o futuro, pois sabem que têm estabilidade, não paira sobre eles o fantasma do desemprego, da instabilidade, da rotatividade. Esses são sentimentos que, muitas vezes, nos tiram a paz (ROSA, Campus 2, 2018).

Destarte, entendemos que fica subentendida uma situação de desvalorização, aliada a uma grande instabilidade e à impotência ou frustração das funcionárias diante da condição profissional. A contratação de profissionais para atuar nos órgãos públicos que não seja por meio do concurso público, ou seja, mediante a terceirização ou contrato temporário, apresenta um lado nefasto que consiste no processo de desumanização do trabalho, pois, através da sua alienação, provoca a perda e a unidade de classe. O trabalhador passa a ser visto como mera mercadoria descartável, e, dessa forma, o ser humano passa a constituir a categoria de objeto, deixa de ser visto como sujeito dotado de dignidade. Antunes e Druck explicam que:

No plano do mercado de trabalho, no qual se estabelecem as relações de compra e venda da força de trabalho, as formas de inserção, os tipos de contrato, os níveis salariais, as jornadas de trabalho, definidos por legislação ou por negociação, expressam um recrudescimento da mercantilização, no qual o capital reafirma a força de trabalho como mercadoria, subordinando os 
trabalhadores a uma lógica em que a flexibilidade, o descarte e a superfluidade são fatores determinantes para um grau de instabilidade e insegurança no trabalho, como nunca antes alcançado (2013, p. 219).

No que se refere ao coletivo de trabalhadores, o contrato temporal fragmenta, divide, aparta, desmembra as identidades coletivas, individualiza e cria concorrência entre os que trabalham no mesmo local, provocando, por vezes, o escalonamento de primeira e de segunda categoria, o que comprova a alienação desses trabalhadores. Apesar de existir diferença entre o regime de trabalho estatutário e o regime de contrato temporário, é válido ressaltar que os dois são sujeitos e objetos do capitalismo que se estende desde a exploração até a alienação e, por vezes, reproduz e reafirma, no fazer pedagógico, a forma exploratória do capitalismo.

De fato, existem diferenças ${ }^{4}$ marcantes entre os funcionários estatutários e os prestadores de serviços. Estas diferenças no regime de trabalho geram nos funcionários das creches da UESB um misto de sentimentos, como insegurança e instabilidade, em razão do desrespeito aos direitos trabalhistas, como relata uma das entrevistadas:

Quase todos são prestadores de serviços, com exceção da coordenadora administrativa que é do quadro efetivo de funcionários da UESB. Alguns funcionários, como da limpeza e a secretária, são terceirizados. E têm as estagiárias que eu não sei o nome que se dá. Sei dizer que são esses estágios têm duração de 2 anos. Nós gostaríamos muito que os professores da creche fossem efetivos, tivessem, assim, seus direitos trabalhistas respeitados. Sou contratada, e paira sobre nós contratados a insegurança, pois o contrato pode ser rescindido a qualquer momento. A nossa vontade é que todos nós fôssemos efetivados (ROSA, Campus 2, 2018).

Quando os profissionais da educação são submetidos ao regime de contrato temporário, é possível perceber a alienação aplicada sobre o sujeito no processo de trabalho produtivo, como também em outras instituições sociais, tais como no campo da cultura e da política, disseminando uma falsa consciência da "naturalização" das relações de desigualdades e exploração, condição vivida pela classe trabalhadora.

A alienação em Marx é entendida como a relação contraditória do trabalhador com o produto de seu trabalho e a relação do trabalhador com o ato de produção, um processo de objetivação, tornando o homem estranho a si mesmo, aos outros homens e ao ambiente em que

\footnotetext{
${ }^{4}$ Em relação às férias, os servidores têm o direito de usufruir 30 dias após 12 meses trabalhados não podendo vendê-las, com direito de optar por gozá-las por 30 dias corridos ou em blocos de 15 dias; já os contratados, seguem as regras da CLT, a cada 12 meses trabalhados, podem usufruir 30 dias de férias, ou tem a opção de vender 1/3 do período. Os servidores estatutários, por direito, possuem a Licença Prêmio, que garante que a cada cinco anos trabalhados, o servidor tenha direito a três meses de afastamento remunerado. Tal benefício não existe no regime CLT, no qual os contratados estão enquadrados. Outro benefício restrito aos servidores estatutários é a estabilidade; após um período de três anos de estágio probatório, quando ocorre a avaliação de desempenho, ao ser aprovado, o servidor adquire a estabilidade.
} 
vive. "A apropriação surge como alienação, e a alienação como apropriação" (MARX, 2002, p. 122). Essa alienação do homem e de seu produto também implica na sua alienação em relação aos outros homens. A pré-condição da existência é o trabalho, mas, no capitalismo, o próprio trabalho transformou-se numa mercadoria.

O trabalhador põe a sua vida no objeto; porém agora ele já não lhe pertence, mas sim ao objeto. Quanto maior a sua atividade, mais o trabalhador se encontra objeto. Assim, quanto maior é o produto, mais ele fica diminuído. Quanto mais valor o trabalhador cria, mais sem valor e mais desprezível se torna. Quanto mais refinado é o produto mais desfigurado o trabalhador (MARX, 2002, p. 112).

Quando se trata do trabalho docente, somos levados pela nossa alienação a termos a ingênua impressão de que somos "detentores do conhecimento" e temos certa "autonomia" no processo de ensino e aprendizagem, o que é muito contraditório, pois vendemos a nossa força de trabalho em troca de salário, de fato, como os outros trabalhadores, para satisfazer às necessidades de primeira ordem, isto é, moradia, saúde, alimentação, etc. E, por vezes, não percebemos que também somos trabalhadores explorados pelo sistema e reproduzimos esse sistema em nossas ações educativas, isso porque a forma histórica que o trabalho assume no modo de produção capitalista é dissimulada, o que não quer dizer que a exploração do trabalhador seja invisível, pelo contrário, é visível, porém mascarada pelo contrato de trabalho e pelo salário.

Este processo de alienação faz com que o salário que o trabalhador recebe no final do dia, da semana, ou do mês, represente apenas parte do tempo pago pelo que produziu de bens ou serviços - a outra parte fica com quem empregou o trabalhador. Parte de seu esforço que tem como resultado mercadorias ou serviços é alienado. Ou seja, é apropriado pelo empregador. O que mascara esta exploração é sua legalização pelo contrato de trabalho (FRIGOTTO, 2002, p. 17).

A sociedade capitalista se destaca por seu poder ideológico, formalizando a exploração através de contratos temporários que, muitas vezes, não servem a outros propósitos que não estejam de acordo com a manutenção das classes sociais. Assim, para compreender como essas determinações e contradições recaem sobre a valorização e a precarização do trabalho docente, Alves (2007, p. 115) pontua que:

A precarização é um processo social de conteúdo histórico-político concreto, de natureza complexa, desigual e combinada, que atinge o mundo do trabalho, principalmente setores mais organizados da classe do proletariado. É difícil falarmos de precarização de trabalhadores proletários que sempre viveram à margem da seguridade social e da legislação previdenciário-trabalhista. 
A precarização do trabalho docente está, portanto, ligada às formas como esse profissional é contratado, tais como através de contrato temporário, em termos de salários, isto é, mão de obra barata, levando-os, assim, a um processo de desprofissionalização da categoria docente, ao se tornarem profissionais contratados temporariamente, podendo, a qualquer momento, serem dispensados do trabalho. Nesse sentido, a terceirização, ou o contrato temporário, surge como uma expressão da atual dinâmica capitalista que, por definição, é uma forma de contratação de mão de obra com ampla disseminação a partir dos anos 1990, com forte tendência à precarização das relações de trabalho, ao aprofundamento das desigualdades e à fragmentação dos trabalhadores. Essa situação pode ser vista tanto na iniciativa privada como nos órgãos públicos.

O trabalho de Lopes (2003) intitulado Universidade Pública e Desenvolvimento local: uma abordagem a partir dos gastos da Universidade Estadual do Sudoeste da Bahia, apresenta o quadro de servidores técnico-administrativos da UESB na época de seu estudo. O autor pontua que o quadro de servidores técnico-administrativos, na época de sua pesquisa, era formado por 347 funcionários, nas seguintes categorias: nível superior, nível médio e nível de apoio. A universidade contava, ainda, com servidores contratados em caráter temporário, em regime especial de trabalho, destacando ainda que além dos funcionários contratados, a UESB tinha prestadores de serviços no campo da segurança e da limpeza.

Evidencia-se que o regime de contrato temporário é algo consolidado dentro do quadro de funcionários da UESB. Como destaca Alves (2005), com o aumento dos profissionais contratados em regime temporário, cresce a desobrigação do Estado na gerência das conquistas sociais e a flexibilização das relações trabalhistas, o que provoca a precarização do trabalho.

É importante ressaltar que, quando tratamos de precarização do trabalho, não significa que a atividade em si é precária, mas o que se quer dizer é que o regime de contrato temporário precariza as relações de trabalho, sendo constatado o recorrente descumprimento das leis trabalhistas, elevada flexibilização e principalmente o sentimento de não pertencimento e distinção em relação aos servidores estatutários. Esse sentimento é notório na fala da funcionária Rosa (Campus 2):

Eu acho que a universidade não valoriza o professor de Educação Infantil que trabalha nas creches. É a universidade que forma os profissionais que atuam nessa modalidade. Contraditoriamente, quando esta instituição passa a ser o empregador, não os valoriza enquanto profissionais. Na verdade, é uma grande discrepância, por exemplo, ao formar um médico enfatizar a importância profissional e oferece um salário irrisório a esse profissional. No nosso caso, o piso salarial é de dois mil e pouco, mas recebemos muito menos que isso, ainda que tenhamos que dar conta de tudo. (ROSA, Campus 2, 2018) 
O depoimento da servidora revela que reconhece o papel social da Universidade de disseminar os conhecimentos historicamente acumulados pela humanidade e de formar quadros profissionais. Fávero $(1989$, p. 42) lembra que a universidade "foi criada não para atender às necessidades fundamentais da realidade da qual é parte, mas pensada e aceita como um bem cultural oferecido a minorias”. Contudo, o mundo capitalista impõe mudanças estruturais, baseadas em uma política de contenções de despesas, que flexibiliza as questões trabalhistas e impulsiona os "novos" arranjos sociais. A respeito disso, Oliveira afirma que:

O aumento dos contratos temporários nas redes públicas de ensino, havendo, em alguns estados, os numerosos correspondentes aos trabalhadores efetivos, o arrocho salarial, respeito a um piso salarial nacional, a inadequação ou mesmo ausência, em alguns casos, de planos de cargos e salários, a perda de garantias trabalhistas e previdenciárias oriundas dos processos de reforma do aparelho do Estado têm tornado cada vez mais agudo o quadro de instabilidade e precarização de emprego no magistério público (2004, p. 140).

De fato, o que se pode afirmar é que se trata de uma prática recorrente, presente em quase todos os segmentos, no âmbito privado e público. Antunes e Druck (2013) esclarecem que a terceirização caracteriza-se pelo processo de contratação da compra e venda de força de trabalho, cujas relações sociais estabelecidas são disfarçadas; há um tratamento de categoria inferiorizada dentro da estrutura da empresa, implicando em jornadas mais extensas, alta rotatividade, pisos salariais mais baixos e maiores riscos de acidentes, reduzindo a mobilização coletiva; muitas vezes, oculta as relações de trabalho, como meio de burlar a legislação vigente.

A precarização do trabalho dos funcionários das creches da UESB perpassa, também, pelo reconhecimento da Educação Infantil dentro da universidade. Nesse sentido, o reconhecimento da creche como parte da estrutura física da UESB é, por vezes, desconsiderado em alguns trabalhos acadêmicos, como o de Lopes (2003), que ao descrever a estrutura da UESB negligencia a existência dessa instituição dentro do espaço físico da universidade (Campus 1).

Cabe ressaltar que, ao analisar os documentos da UESB, como o Regimento, o Estatuto e o Plano de Desenvolvimento Institucional - PDI (2013-2017), constatamos que apenas o PDI faz menção à existência da creche no Campus universitário:

A UESB dispõe de órgãos suplementares com finalidade social, científica, cultural, técnica e esportiva para integrar suas atividades com a comunidade interna e com a sociedade. Esses órgãos estão subordinados administrativamente à Reitoria/Pró-reitoria e/ou vinculados academicamente aos Departamentos: Museu Pedagógico Padre Palmeira; Núcleo de Direito da Criança e do Adolescente; Núcleo de Práticas Jurídicas; Clínica Psicológica; 
Clínica Odontológica Universitária; Creche de Educação Infantil; PROLER; Projeto Janela Indiscreta; Teatro Glauber Rocha; Órgão de Educação e Relações Étnicas da UESB (ODEERE); Centro de Estudos da Leitura em Jequié; Ludoteca em Jequié e Itapetinga; Núcleos diversos, entre outros (PDI/ UESB, 2013-2017, p. 24, grifos nossos).

Essa falta de reconhecimento também pode ser observada no site da UESB, quando apresenta o Campus de Vitória da Conquista sem fazer menção à existência de uma creche em seu interior:

O Campus conta com mais de 80 laboratórios, onde são desenvolvidas atividades de pesquisa que proporcionam ao estudante a experiência de uma formação contundente. Um Centro de Extensão e Ações Comunitárias; dois Museus: Padre Palmeira e Henriqueta Prates; Núcleos de Prática Jurídica e de Defesa da Criança e do Adolescente são alguns dos espaços a serviço do estudante, determinantes para que o Ensino seja sólido, por meio da prática da Extensão e da Pesquisa. O Campus conta, ainda, com o Centro Universitário de Atenção à Saúde (Ceuas), que serve como laboratório para os estudantes de Medicina, e, ao mesmo tempo, presta um importante serviço à população local, através do oferecimento de atendimentos médicos gratuitos em diversas especialidades. Também no Campus de Vitória da Conquista, a Uesb dispõe de restaurante e residência universitários (UESB, 2018).

Esses fatos indicam a ausência de reconhecimento dessas unidades no interior da própria Universidade. Essa realidade não é algo inerente somente à UESB, uma vez que Marciel (1994) pontua que o trabalho com o pré-escolar não é prioridade dentro do sistema universitário.

No que diz respeito à pré-escola da Universidade, percebi que existe uma dicotomia entre os profissionais que trabalham na pré-escola e a estrutura universitária. Existe um déficit de investimento por parte da Universidade no trabalho pré-escolar realizado pelos profissionais daquela instituição, ou seja, o pré-escolar não é uma prioridade dentro do sistema universitário e isso é flagrante, já que os próprios estudantes e muitos funcionários e professores não sabem sequer da existência da pré-escola dentro da UFRJ (MARCIEL, 1994, p. 76).

Desse modo, as funcionárias entrevistadas relatam sentimentos de invisibilidade dentro desse espaço do âmbito universitário.

Seria interessante que o olhar fosse outro, mas hoje percebo que o olhar ainda é muito minimizado. Aqui poderia ser um espaço de um rico laboratório, mas que não é explorado, é, muitas vezes, desconsiderado (ROSA, Campus 2, 2018).

A fala da funcionária revela uma visão ampla do que seria a Educação Infantil no Campus universitário, que poderia ser explorada como campo de estágio e de desenvolvimento de pesquisa. Essa mesma perspectiva foi pontuada por uma das mães de aluno. 
O nosso sonho de mães servidoras enquanto buscávamos a creche no espaço universitário, era que esse espaço fosse utilizado como um grande laboratório, pois, assim, entendo que tanto as crianças ganhariam com as atividades propostas pelos estudantes, como os estudantes teriam uma experiência de grande valia, pois a universidade é um espaço rico em conhecimento (BROMÉLIA Campus 2, 2018).

Raupp pontua que todas as unidades de Educação Infantil nas universidades federais desenvolvem uma série de outras atividades.

Praticamente todas as unidades são também campo de pesquisa e de observações, ou seja, dispõe sua estrutura de funcionamento as profissionais das múltiplas áreas de conhecimento da universidade para coleta de dados de pesquisa ou para observações $(2002$, p. 72$)$.

Nesse sentido, Rocha (2001) destaca a integração alcançada em algumas instituições de ensino superior com as creches e pré-escolas, através de projetos de intervenção com a forma de estágios.

Raupp assevera que:

No caso brasileiro, múltiplas são as áreas que buscam as unidades de educação infantil como campo de estágio e de desenvolvimento de profissionais. Para além da pedagogia, também as áreas de psicologia, educação física, enfermagem, odontologia, nutrição, música, belas artes, desenho industrial, fonoaudiologia, letras, jornalismo, agronomia, economia doméstica, fisioterapia, farmácia, serviço social, medicina, artes plásticas, teatro e dança demonstra o grande interesse que a educação das crianças pequenas vem despertando (2002, p. 74).

Assim, quando a creche universitária é envolvida pelo tripé que norteia os trabalhos universitários, ela passa a fazer parte efetiva da "engrenagem” universitária e, assim, justifica sua existência para além do princípio do ensino, tendo outras perspectivas, como pesquisa, campo de estágios e extensão.

\section{Considerações finais}

No caminhar desta investigação pudemos identificar alguns determinantes históricos que contribuíram para a criação das creches da UESB, pois sua implementação está vinculada às reivindicações trabalhistas, respaldadas nas legislações e no movimento feminista em prol da luta por creches em locais de trabalho, ou seja, a motivação pelas creches da UESB foi um movimento externo à necessidade da criança, como aponta a origem das creches no Brasil. Esse processo histórico que antecedeu a implementação da creche definiu uma identidade de benefício social, a princípio aos servidores e professores da universidade, e, posteriormente, 
aos alunos. É possível perceber que não existe uma identidade institucional definida nas creches da instituição estudada, o seu trabalho transita entre o assistencialismo, a educação ou o aspecto acadêmico. Esse entrave é ponto de debate não só local, mas se apresenta como uma questão a nível nacional, em relação às creches universitárias.

Ao longo deste estudo, deparamos com entraves que limitaram o acesso a dados relevantes, dentre os quais: a falta de informações e de registros referentes ao processo de implementação das creches; falta de documentos relacionados aos recursos financeiros e a não disponibilização de alguns dos documentos da instituição estudada pelos funcionários responsáveis.

Não encontramos nenhum dispositivo legal tratando, explicitamente, da instituição de creches nas universidades, em específico na Universidade Estadual do Sudoeste da Bahia. A matéria foi contemplada, de forma ampla (para toda a Administração Pública Federal), por meio de Decretos que dizem respeito à assistência pré-escolar.

Dessa forma, investigar o processo de implementação das creches da UESB possibilitou-nos visualizar a tramitação desta modalidade de ensino - a Educação Infantil - no interior da universidade, onde, por vezes, é desconsiderada. Sobretudo, é necessário que as creches da UESB tenham uma atenção maior do que têm recebido até o presente momento pela comunidade universitária. É indispensável que as creches da UESB sejam reconhecidas como unidades na estrutura administrativa da universidade.

O estudo demostrou que as creches na UESB estão vinculadas a órgãos que não são “da Educação", como a Pró-Reitoria de Recursos Humanos, sendo pertinente refletir sobre a sua vinculação a setores administrativos que não sejam da área acadêmica, o que contribui para o não reconhecimento de sua identidade educacional. É preciso que a universidade compreenda a função educativa das creches e reconheça a qualidade dos serviços que vêm sendo ofertados nessas instituições. De forma similar, é fundamental que as creches da UESB ampliem suas atividades para além da educação das crianças, incorporando os propósitos das atividades fins da universidade: ensino, pesquisa e extensão.

As universidades públicas brasileiras estão passando por um processo de reforma orçamentária e enfrentam muitas dificuldades decorrentes de uma política neoliberal que impulsiona o Estado a ser mínimo para as políticas educacionais e sociais. Diante dessa conjuntura nacional, reafirmamos a importância da existência das unidades de Educação Infantil no interior da UESB, permitindo a garantia do direito à educação, ao compreender que se trata de um direito constitucional, direito este que deve ser assegurado a todas as crianças brasileiras. 
Portanto, destacamos a necessidade de se pensar a situação contratual do quadro de profissionais das creches com o intuito de se valorizar e reconhecer esses profissionais, dandolhes o direito de possuir um plano de carreira no qual se reconheça a importância do seu trabalho.

\section{REFERÊNCIAS}

ALVES, G. O novo e precário mundo do trabalho restruturação produtiva e crise do sindicalismo. São Paulo: Boitempo, 2005.

ALVES, G. Dimensões da reestruturação produtiva: ensaios de sociologia do trabalho. 2 ed. Londrina: Praxis; Bauru: Canal 6, 2007.

ANTUNES, R.; DRUCK, G. A terceirização como regra? Revista TST, Brasília, v. 79, n. 4, out./dez. 2013.

FAGUNDES, M. dos R. A creche no trabalho... o trabalho na creche: um estudo sobre o Centro de Convivência Infantil da Unicamp: trajetória e perspectivas. Orientadora: Ana Lúcia Goulart Faria. 1997. 179f. Dissertação (Mestrado em Educação) - Universidade Estadual de Campinas, Faculdade de Educação, Campinas, SP, 1997. Disponível em:

http://www.repositorio.unicamp.br/handle/REPOSIP/252739. Acesso em: 14 jan. 2020.

FÁVERO, M. de L. de. A universidade em questão: como resgatar suas relações fundamentais? In: VIEIRA, S. L. V. et al. (Org.). A Universidade em Questão. São Paulo: Autores Associados, p. 41-54, 1989.

FRIGOTTO, G.; CIAVATTA, M. A Experiência do trabalho e a Educação Básica. Rio de Janeiro: DP\& A, 2002.

HADDAD, L. A creche em busca da identidade: perspectivas e conflitos na construção de um projeto educativo. 2. ed. São Paulo: Quiron; Loyola, 1993.

LOPES, R. P. M. Universidade pública e desenvolvimento local: uma abordagem a partir dos gastos da Universidade Estadual do Sudoeste da Bahia. Vitória da Conquista: Edições UESB, 217 p., 2003.

LUDKE, M.; ANDRÉ, M. Pesquisa em educação: abordagens qualitativas. São Paulo: EPU, 1986.

MARCIEL, M. de A. Com quem ficam as crianças? um estudo da relação casa/escola no espaço pré-escolar. 1994. Dissertação (Mestrado em Educação). Universidade Federal do Rio de Janeiro, Rio de Janeiro, 1994.

MARX, K.; ENGELS, F. A ideologia alemã. Trad. de Luiz Cláudio de Castro e Costa. São Paulo: Martins Fontes, 1998.

MARX, K. O capital: crítica da economia política. Trad. de Reginaldo Sant'Anna. 19 ed. Rio 
de Janeiro: Civilização Brasileira, 2002.

OLIVEIRA, D. A. A reestruturação do trabalho docente: precarização e flexibilização. Educação e Sociedade, v. 25, n. 89, 2004.

RAUPP, M. D. A Educação infantil nas universidades federais. 2002. 142f. Dissertação (Mestrado em Educação). Universidade Federal de Santa Catarina - UFSC, Santa Catarina, 2002.

ROCHA, E. A. C. A pesquisa em educação infantil no Brasil: trajetória recente e perspectivas de consolidação de uma pedagogia da educação infantil. Florianópolis: UFSC, 2001.

ROSEMBERG, F. A educação pré-escolar brasileira durante os governos militares. Cadernos de Pesquisa. n. 82. São Paulo: Fundação Carlos Chagas, ago. 1992.

SAVIANI, D. A política educacional no Brasil. In: STEPHANOU, M.; BASTOS, M. H. (Orgs.). Histórias e memórias da educação no Brasil. v. 3: Petrópolis, Rio de Janeiro: vozes, 2005.

UESB. Documento de implantação da Creche Bem Querer, Campus de Vitória da Conquista, Bahia, 1988.

UESB. Documento de implantação da Creche Casinha do Sol, Campus de Jequié, Bahia, 1998.

UESB. Informativo Creche Casinha do Sol, Campus de Jequié, Bahia, 2016.

UESB. Plano de Desenvolvimento Institucional - PDI (2013-2017).

UESB. Nossos Campi. Campus de Vitória da Conquista. Vitória da Conquista, Bahia, 2018. Disponível em: http://www2.uesb.br/nossos-campi/vitoria-da-conquista/. Acesso em: 10 jun. 2018.

\section{Como referenciar este artigo}

ARAÚJO, S. B.; PIRES, E. D. P. B.; RIBAS, G. F. Valorização, precarização e reconhecimento dos professores de creches universitárias. Revista Ibero-Americana de Estudos em Educação, Araraquara, v. 15, n. 1, p. 221-235, jan./mar., 2020. e-ISSN: 1982-5587. DOI: https://doi.org/10.21723/riaee.v15i1.12780

Submetido em: 23/07/2019

Revisões requeridas: 29/07/2019

Aceito em: 10/09/2019

Publicado em: 02/01/2020 